\title{
A EXPANSÃO DOS GRUPOS ESCOLARES EM MINAS GERAIS NA PRIMEIRA REPÚBLICA: ESTUDO COMPARADO SOBRE A INTERIORIZAÇÃO DO ENSINO PRIMÁRIO NA ZONA DA MATA
}

\author{
Talitha Estevam Moreira Cabral ${ }^{1}$ \\ Giovanna Maria Abrantes Carvas ${ }^{1}$ \\ Denilson Santos de Azevedo ${ }^{1}$
}

\begin{abstract}
RESUMO
O presente artigo apresenta alguns dos resultados de uma investigação sobre o processo de criação e os primeiros anos de funcionamento de dois grupos escolares de Minas Gerais, pioneiros em seus municípios. Por serem contemporâneos e estarem localizados em duas cidades distintas pertencentes à mesma região mineira, a Zona da Mata, buscamos realizar um estudo comparado entre estes dois educandários: o Grupo Escolar Silveira Brum (GESB), criado em Muriaé, e o Grupo Escolar Antônio Martins (GEAM), criado em Ponte Nova. Tal estudo se faz pertinente devido à ausência de estudos sistematizados sobre a temática, o que nos possibilitará perceber as leis emanadas do Estado, através da Secretaria do Interior, e como elas estavam se efetivando nos municípios mineiros no início do século $\mathrm{XX}$.
\end{abstract}

Palavras-chave: Grupos Escolares; História comparada; Estado de Minas Gerais.

\section{THE EXPANSION OF SCHOOL GROUPS IN MINAS GERAIS IN THE FIRST REPUBLIC: COMPARATIVE STUDY ON INTERIORIZATION OF PRIMARY EDUCATION IN THE "ZONA DA MATA".}

\begin{abstract}
This article presents some results of an investigation into the process of creation and the first years of operation of two school groups from Minas Gerais, pioneers in their municipalities. Why are contemporary and are located in two different cities within the same mining area, the Zona da Mata, seek conduct a comparative study between these two Educational establishments: the School Group Silveira Brum (PSWB), created in Muriaé, and Antonio Martins School Group (GEAM), created in Ponte Nova. This study is relevant because of the absence of systematic studies on the subject, which will enable us to understand the laws issued by the State, through the Department of the Interior, and how they were effecting the municipalities miners in the early twentieth century.
\end{abstract}

Keywords: School Groups; Comparative History; State of Minas Gerais. 


\section{Introdução}

O presente trabalho analisa aspectos relacionados à história regional e à história da educação comparada apresentando resultados da investigação documental, iconográfica e de memória sobre o processo de criação e as duas primeiras décadas de funcionamento de dois grupos escolares, ambos localizados na região da Zona da Mata do estado de Minas Gerais. Tais educandários foram pioneiros nesta modalidade de ensino nos municípios de Muriaé e Ponte Nova.

O estudo trata, respectivamente, da origem e desenvolvimento do Grupo Escolar Silveira Brum (GESB), criado em Muriaé pelo decreto 3.305, de 5 de setembro de 1911 e instalado em 7 de agosto de 1912, e do Grupo Escolar Antônio Martins (GEAM), criado em Ponte Nova pelo Decreto ${ }^{\circ}$. 3805, de 18 de janeiro de 1913 e instalado em 03 de maio do mesmo ano. Por serem praticamente coetâneos e estarem situados em duas cidades distintas, porém relativamente próximas (distam cerca de $100 \mathrm{~km}$ ), buscamos realizar um estudo comparado entre estes dois estabelecimentos de ensino primário, no período que vai de 1910 a 1930, com o propósito de identificar características que os aproximam ou os diferenciam, em termos estruturais, de procedimentos pedagógicos e práticas educativas.

A pesquisa se justifica pela ausência de trabalhos sobre essa temática específica, e também pela comemoração do centenário recente dessas instituições escolares, que ainda hoje estão em funcionamento, sendo atualmente denominadas de Escola Estadual Doutor Silveira Brum e Escola Estadual Senador Antônio Martins, respectivamente. Isso reforça a relevância dessa investigação mais sistematizada sobre a história comparada da origem e constituição desses estabelecimentos de ensino nos seus primórdios.

Pretende-se, então, neste trabalho, estabelecer alguns aportes teóricos relacionados à história comparada e à educação, sobretudo no que se refere à dimensão temporal e metodológica. Buscar-se-á enfatizar as características sociais e econômicas dos municípios mineiros supracitados no período em foco, apresentando alguns aspectos da história educacional desses dois grupos escolares públicos. Serão destacados os repertórios temáticos tratados no cotidiano pedagógico e escolar nos quais esses educandários se assemelharam ou divergem nos seus primeiros anos de funcionamento.

Outro objetivo pretendido é o de compreender como as diretrizes educacionais e as normas regimentais emanadas da Secretaria do Interior do governo do Estado de Minas Gerais da época, se consubstanciaram no âmbito da gestão local e como isso se refletia na prática pedagógica desenvolvida nos Grupos em tela.

Para a consecução deste trabalho, realizou-se uma revisão bibliográfica sobre a criação, constituição e disseminação dos grupos escolares no Brasil e, particularmente, no Estado de Minas Gerais. Também foram realizadas visitas ao arquivo existente nessas instituições de ensino e ao Arquivo Público Mineiro (Belo Horizonte) - em busca de documentos primários escolares, como atas, termos de posse, de visitas, relatórios, dentre outros. Também foram feitas visitas nos acervos existentes nos arquivos municipais das Prefeituras de Muriaé e Ponte Nova, principalmente em busca de jornais da época, que trazem notícias a respeito da luta local empreendida para o processo de criação das escolas, as estatísticas sobre matrículas iniciais e finais de alunos, de comemoração de eventos cívicos e educacionais acontecidos em diferentes datas nestas instituições.

A pesquisa focou, primeiramente, as características sociais, econômicas, políticas e educacionais desses dois municípios e as injunções que possibilitaram a criação e instalação dos grupos escolares. Com efeito, pode-se verificar que ambos os municípios apresentaram um crescimento urbano mais significativo no limiar do século $\mathrm{XX}$, não obstante a concentração demográfica e de atividades econômicas ainda estarem assentadas 
de modo disperso no meio rural, com o predomínio da economia cafeeira no município de Muriaé e da economia açucareira em Ponte Nova.

No caso de Muriaé, o progresso foi constante, principalmente a partir de 1886, com a inauguração da Estação da Estrada de Ferro Leopoldina que ligava diariamente o município à então capital do Império (Rio de Janeiro). Em relação à Ponte Nova, ressaltase o surto desenvolvimentista pelo qual a cidade veio passando desde o início do século $\mathrm{XX}$, com a chegada da energia elétrica e o fortalecimento da agroindústria açucareira.

Também se procurou averiguar qual a situação educacional desses dois municípios, anteriormente à instalação dos grupos escolares. Nesse sentido, a cidade de Muriaé só dispunha de ensino de alfabetização ministrado por professores particulares nas casas de ensino, nas escolas isoladas ou por meio de aulas avulsas. Em Ponte Nova, o modelo de ensino vigente é praticamente o mesmo, baseado nas escolas domésticas, regidas por apenas um professor, que normalmente era o dono da cadeira e remunerado pelo poder público. Detecta-se a presença de uma escola confessional, a Escola Normal Nossa Senhora Auxiliadora, em Ponte Nova, destinada à formação de professores e criada em 1898, sob a direção da congregação salesiana.

Quanto à demanda pela criação e instalação dos grupos escolares, verifica-se que essa luta nos municípios estudados se intensifica após a Reforma de Ensino efetuada no governo de João Pinheiro, no Estado de Minas Gerais (1906), que elegeu esse modelo de escola como ideal para a difusão do método seriado e simultâneo do ensino. A inauguração dos primeiros grupos em Belo Horizonte (1907), Juiz de Fora (1908) e Lavras (1909), desencadeou uma emulação regional entre os municípios e suas lideranças políticas pela primazia da instalação destes estabelecimentos educacionais, que teriam um significado simbólico de prestígio, civilidade e progresso para os municípios que o sediassem. Daí que a edificação do Grupo será realizada pelo poder público local e normalmente se localizará na praça central da cidade, geralmente ao lado da Igreja matriz e da Câmara de Vereadores.

Já a autorização para o início do funcionamento, a contratação dos docentes e servidores ficava a cargo do governo estadual. Nesse sentido, a construção do GESB estará concluída em setembro de 1911, mas o início das aulas só ocorrerá em agosto de 1912. No que diz respeito à obra do GEAM, ela acontecera no fim de 1910, embora as atividades escolares só começaram três anos mais tarde, em maio de 1913. Quanto aos principais entraves que impediram a breve inauguração do estabelecimento após a conclusão de suas obras destaca-se a nomeação do diretor, dos professores e demais funcionários, bem como a assinatura do decreto de criação por parte do Governo mineiro.

$\mathrm{O}$ início do funcionamento desses grupos e suas trajetórias institucionais, pedagógicas e educativas até o ano de 1930, podem em parte ser elucidadas por meio da leitura e interpretação de documentos seriais ou não, emitidos e recebidos por estes estabelecimentos de ensino, pelos registros dos visitantes, profissionais ou não da educação, e por notícias impressas veiculadas pelos periódicos locais. A escolha por essa demarcação temporal se fez por entendemos ser este um período de tempo suficiente para uma apreensão aproximada da identidade institucional que vai se constituindo.

Durante a pesquisa realizada, a comparação entre as questões relativas ao desdobramento dos turnos, à disparidade entre os dados iniciais e finais de matrícula e à frequência aos Grupos, as características dos professores quanto à formação e ingresso na carreira, o perfil dos diretores, no que se refere principalmente a forma de condução dos trabalhos escolares, bem como alguns apontamentos do cotidiano, que dizem respeito à difusão dos preceitos republicanos por meio de atividades pedagógicas e as festividades de cunho patriótico, demonstram aproximações e singularidades existentes entre esses dois 
estabelecimentos de ensino, em meio a um movimento mais amplo de difusão e de reforma do ensino primário, que se iniciou após o advento da República no Brasil.

A criação do GESB e do GEAM representou uma parte do processo de expansão desse modelo de escolarização inovador que se disseminou gradativamente pelo Estado de Minas Gerais e por vários estados brasileiros. No caso de Minas Gerais, o estudo comparado sobre a interiorização desses estabelecimentos de ensino em uma pequena região da zona da mata, possibilitou verificar como as diretrizes foram implementadas e que nuances diferenciaram a criação e a trajetória dessas duas instituições de ensino centenárias.

A fim de conhecer parte da história educacional dos dois primeiros grupos escolares públicos dos municípios mineiros supracitados buscaremos apresentar brevemente uma revisão de literatura sobre a criação dos Grupos Escolares no período da Primeira Republica para, posteriormente, analisarmos aspectos relativos à criação dos Grupos e as características mais relevantes de cada um deles, por meio da análise dos documentos encontrados, para em seguida iniciarmos o estudo comparado.

Muito já foi escrito sobre a formação dos Grupos Escolares no Brasil. Com base nestes estudos detectamos que a organização do ensino primário brasileiro durante $o$ Império (1822-1889) se fez por meio das escolas isoladas. Nesse modelo de ensino, o trabalho era de responsabilidade de um único professor da comunidade, que se tornava o dono de sua cadeira. As classes eram heterogêneas e funcionavam de maneira precária, em locais improvisados, comumente na própria residência dos docentes, quase sempre sem oferecer as mínimas condições de higiene.

A partir de 1889, com a instalação da República, esse modelo de escola passa a ser visto como ultrapassado e incapaz de atender aos ideais propagados pelos defensores do novo regime, como democracia, ordem, progresso e amor à pátria. Daí, gradativamente, vai se difundindo a concepção e implantação de uma nova organização do ensino primário, calcada nos moldes dos grupos escolares, com o agrupamento de várias escolas isoladas em um mesmo prédio, onde deveria ser oferecido um ensino público, laico e universal, formando classes com alunos de mesmo nível de aprendizagem. A nova metodologia adotada para esse modelo educacional foi baseada no método intuitivo.

A instituição desse modelo de ensino e a construção dos grupos foram se propagando, porém em ritmo diferenciado nos vários estados brasileiros. Coube ao então Distrito Federal, na época no Rio de Janeiro e ao Estado de São Paulo o pioneirismo dessa implantação.

Em Minas Gerais a definição dos grupos escolares como espaço ideal para efetivar o ensino primário ocorreu com a edição da lei $n^{\circ} 439$, de 28/09/1906, durante o governo de João Pinheiro. No entanto, mesmo implantada, esta lei não garantiu que os grupos escolares se instalassem de maneira uniforme nos municípios mineiros. Segundo Pereira (2004), após a instituição dessa Reforma foi fundado o primeiro grupo escolar de Minas Gerais, na capital Belo Horizonte, que entrou em funcionamento no dia 05/02/1907. Em seguida foi inaugurado o segundo na cidade de Juiz de Fora e o terceiro em Lavras. Depois deles esse novo modelo de escola foi se difundindo por todo o estado, em tempos diferentes.

\section{O processo de criação e instalação do GESB e do GEAM}

A criação do GESB foi a primeira iniciativa no município de Muriaé, de institucionalizar a escolarização que já se desenvolvia no estado mineiro. O Grupo foi fundado por iniciativa da Câmara Municipal Muriaeense que tinha como presidente o 
vereador Antônio da Silveira Brum ${ }^{2}$. Todavia, problemas de ordem financeira dificultaram sua edificação, visto que essa entidade tinha que arcar com as dívidas legadas pelo Conselho Distrital. Além dessa dificuldade, a pouca influência do município no jogo da política estadual mineira era um desafio a mais para o gestor efetivar a instalação desse estabelecimento de ensino.

Os apelos e as insistentes investidas do poder executivo muriaeense junto ao governo estadual pavimentou a construção da Escola. Conforme correspondência enviada, em 22 de março de 1913, pelo então vereador municipal Antonio José da Silveira Freitas ao então Secretário do Interior, Delfim Moreira, o GESB custou 65:000\$000, sendo que a Câmara Municipal custeou 77\% da obra e o estado contribuiu com apenas 15:000\$000 (23\%). Criado pelo decreto de 05/09/1911, o GESB foi inaugurado em 07/08/1912 sob a direção do professor José Gonçalves Couto, nomeado pelo então presidente do Estado Júlio Bueno Brandão, em 12/01/1912, tal diretor permaneceu no cargo até se aposentar em 13/04/1936.

No que refere ao prédio, o Grupo sobressaía-se como um dos melhores edifícios da cidade, conforme registrado no "Relatório do Movimento do Grupo Escolar de Muriahé", feito pelo diretor, no período de 07/08/1912 a 25/01/1913. Construído exclusivamente para o fim da instrução, o prédio ocupava posição central na cidade, localizado na praça mais movimentada, próxima à Igreja Matriz e ao Edifício da Câmara Municipal.

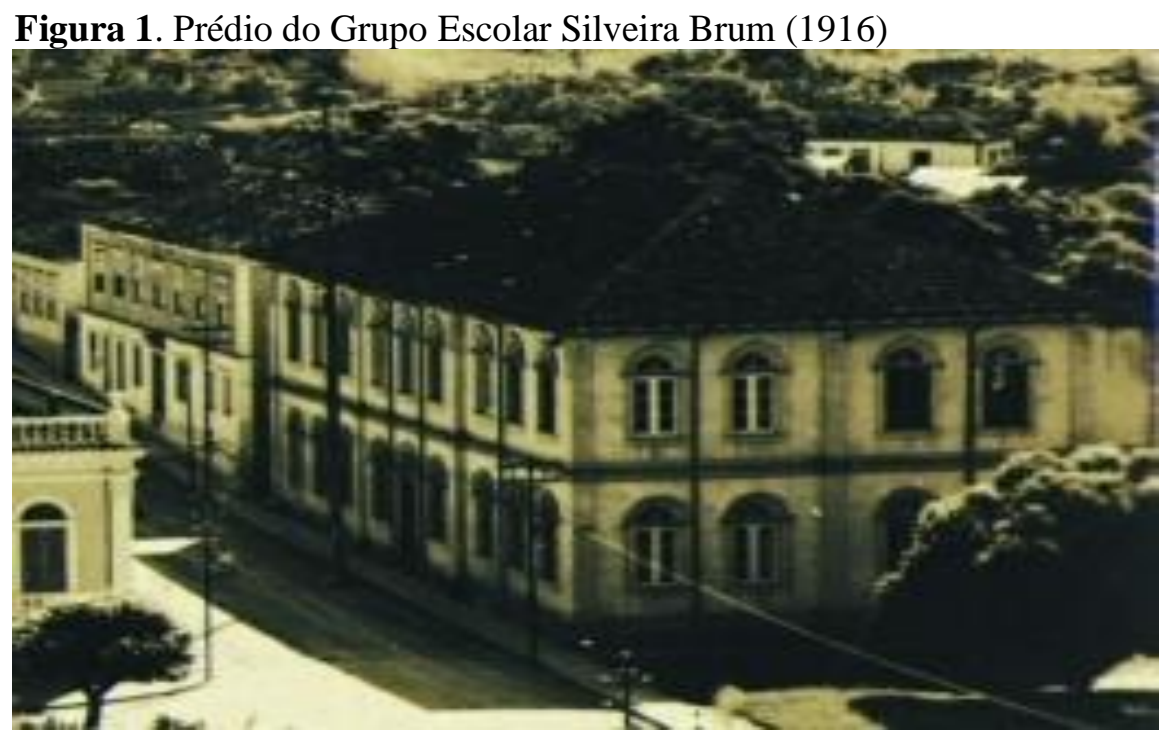

Fonte: Arquivo Municipal de Muriaé

Já o GEAM foi criado pelo decreto $\mathrm{n}^{\circ} 3805$ de 28/01/1913, iniciando suas atividades em 03/05/1913. Sua construção começa na gestão municipal do Major Manoel Olímpio Soares, (04/01/1905 a 31/12/1907), conforme revelam algumas atas da Câmara Municipal. Isso que demonstra que o município foi coetâneo ao movimento educacional que começava a se fortalecer no Estado de Minas. Parece que essa empreitada fazia parte do surto desenvolvimentista pelo qual a cidade vinha passando desde o início do século XX com a chegada da energia elétrica e a criação da primeira indústria açucareira do município, que assinala certa ruptura com o Império e assunção gradativa de ares republicanos, segundo Assis e Azevedo (2008).

O local escolhido para a instalação do Grupo seguiu a tendência de outras cidades, ou seja, foi erguido na praça central da cidade, ocupando um lugar de grande destaque e visibilidade, próximo aos mais vistosos prédios públicos. 
Figura 2. Largo da Matriz da cidade de Ponte Nova, 1910. A direita visualiza-se o terreno adquirido para a construção do Grupo Escolar, ao lado da Igreja de São Sebastião.

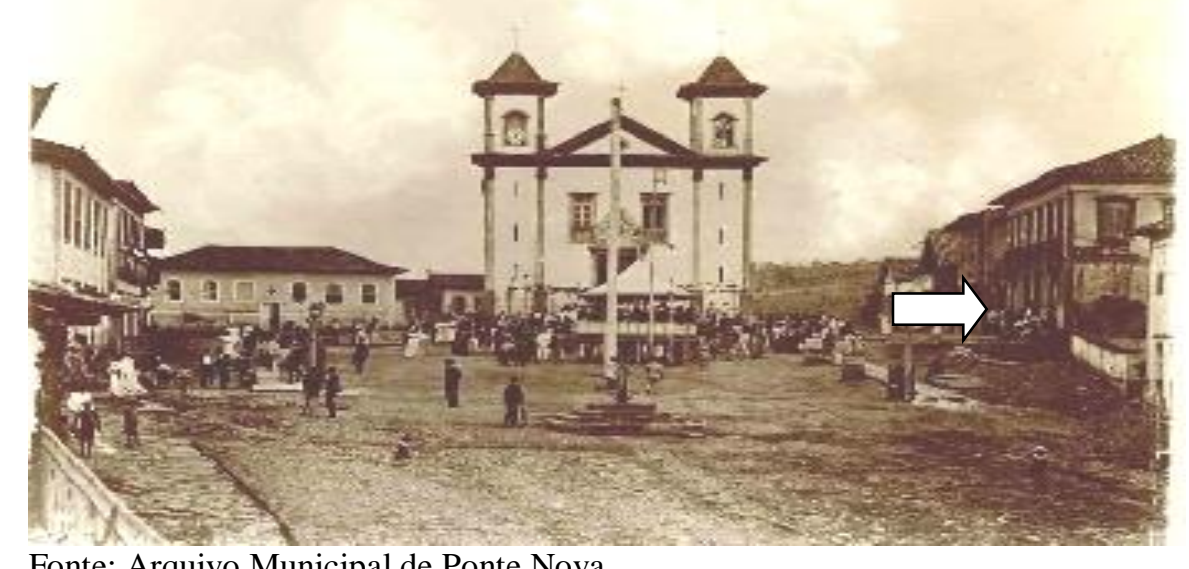

Fonte: Arquivo Municipal de Ponte Nova

Em 1910, ou seja, três anos após o seu início, foram finalizadas as obras de construção do GEAM. Restava ainda a assinatura do decreto de criação por parte do governo mineiro para realizar a contratação de funcionários e professores e designar um nome para assumir o cargo de direção no estabelecimento. Para a realização dessas providências mais três anos se passaram, já que apenas em maio de 1913 o GEAM passou a funcionar e desempenhar seu papel educacional na cidade, sob os cuidados do então diretor escolar Mário Carneiro Fontoura.

Cabe ressaltar que, na década de 1930, o Grupo mudou de sede, recebendo novas instalações e passando a funcionar em novo endereço, em virtude da grande demanda e do elevado número de alunos atendidos anualmente.

\section{GEAM e GESB: aspectos de um estudo comparado}

Uma primeira particularidade acerca do estudo realizado diz respeito à documentação encontrada sobre o primeiro Grupo Escolar pontenovense, uma vez que, sobre este estabelecimento, foram localizados alguns periódicos de circulação local da época em foco, o que não foi possível na cidade de Muriaé, visto que um incêndio ocorrido em 1998 no Arquivo Municipal destruiu vários tipos de documentos contidos no acervo e não foram encontrados nem identificados periódicos locais deste período. No caso de Ponte Nova, o manuseio desta fonte documental contribuiu para o entendimento do papel que o Grupo desempenhou na sociedade pontenovense da época, por meio da identificação de convites para as festividades escolares, das informações sobre a Caixa Escolar, dos exames finais e das noticias relativas à educação, tanto em âmbito estadual quanto regional, veiculadas por esses impressos.

Entre os aspectos observados a respeito dos Grupos Escolares em questão, percebemos que ambos assumiram a nova concepção educacional que estava sendo difundida em nossa sociedade, baseada nos preceitos pregados pela República, inspirados nos ideais de "Ordem e Progresso". Exemplo disso são as festas escolares realizadas nestes locais, que estavam relacionadas às datas cívicas e aos princípios patrióticos.

No relatório de funcionamento do ano de 1915, o diretor do GESB, José Gonçalves Couto, aponta as festividades comemoradas na escola no decorrer do ano de 1914: "o dia 7 
de agosto - aniversário do Grupo - 7 de setembro e 19 de novembro foram mais solenemente festejados. No dia 19 deste mez houve a solennidade da entrega de certificados de approvaçação dos alumnos que concluíram o curso." (GRUPO ESCOLAR SILVEIRA BRUM, relatório do diretor, 1915, s/p).

Neste excerto verifica-se a magnitude dos eventos relacionados com as datas cívicas do calendário. Essa era uma maneira de dar visibilidade às novas práticas pedagógicas implementadas, conforme observa Lopes (2006, p. 2):

em que pese as multiplicidades de usos, intencionalidades e sentidos existentes nas festas, estas eram utilizadas pelas escolas reunidas e grupos escolares, especialmente, para tornar mais visível sua ação pedagógica no contexto escolar, demarcando sua posição de importante inovação no aparato escolar existente. Reunião e movimentação de um número significativo de alunos, as festas escolares demarcavam mobilidade e status das escolas na cidade. Assim, os grupos escolares, no período analisado, situados no topo da hierarquia do sistema de ensino primário, participavam crescentemente das festividades públicas. Seus alunos passavam, cada vez mais, a figurar nas solenidades públicas discursando em nome delas.

Essa situação também ocorria no GEAM, conforme se verifica no primeiro relatório anual enviado à Secretaria do Interior, em 1914, que revela os acontecimentos relativos ao ano, em especial as festividades realizadas:

\begin{abstract}
Além da festa da instalação, em 03 de maio, o estabelecimento comemorou ainda as datas de 13 de maio (abolição da escravatura) e de 19 de novembro (dia da bandeira). A $1^{\text {a }}$ com uma importante passeata pelas ruas da cidade e a $2^{\mathrm{a}}$ com uma seção solene, realizada no salão nobre do edifício escolar. Na festa inaugural presidida pelo Sr. Dr. Caetano Marinho, digno agente executivo do município, foi lançada, pelo referido cavalheiro a idéia da criação da Caixa escolar, anexa ao Grupo (GRUPO ESCOLAR ANTÔNIO MARTINS, Relatório do movimento escolar, 1914, s/p).
\end{abstract}

Quanto aos festejos escolares e ao caráter patriótico das comemorações, Faria Filho (2000) ressalta que as festas cívicas e o hasteamento da bandeira nacional eram pensados pelos grupos escolares como um espetáculo formativo de sensibilidade patriótica e do respeito ao regime republicano. Além dos festejos escolares estarem intimamente relacionados às propostas de "Ordem e Progresso" difundidas pela República, as aulas nos dois Grupos também seguia uma diretriz patriótica, com a presença de aulas de "Instrução Moral e Cívica" em seus programas.

A responsabilidade de manter a ordem e fiscalizar rigorosamente as atividades desenvolvidas ficava a cargo dos diretores, que estiveram vinculados aos respectivos estabelecimentos de ensino durante bastante tempo. No GEAM, Mário Carneiro Fontoura permaneceu no cargo por 27 anos ininterruptos (1913 -1940) e no GESB, José Gonçalves Couto, esteve à frente do educandário por 24 anos (1912-1936).

No exercício desta função dirigente transparece ainda, na análise de alguns documentos, a postura rigorosa assumida pelos dois diretores. Em alguns jornais que circularam em Ponte Nova, durante o período em foco, identificamos a publicação de várias notas a respeito do trabalho desenvolvido pelo diretor do Grupo, sempre fazendo 
menção à sua severidade e competência. Já em Muriaé, localizamos um relato de visita de particulares datado de 10/12/1912, apontando que o Grupo "dispõe de um corpo docente idôneo e de um director, que sabe capturar os visitantes e imprimir ao Grupo uma direcção intelligente e firme".

Nota-se que o controle e a vigilância nas condutas exercida pelos diretores fazia parte do cotidiano da vida escolar e do tempo da escola, tanto dos professores quanto dos alunos. Pode-se comprovar essa afirmação na carta enviada por Gonçalves Couto aos pais de um aluno, queixando-se da indisciplina do menino:

Levo ao vosso conhecimento, para os devidos fins, que o vosso filho [...], alumno deste Grupo, tem procedido muito mal em classe, conforme notas e communicações de sua professora. As penas estabelecidas pelo "Código Disciplinar"- admoestação, reprehensão, más notas, exclusão dos prêmios escolares, privação do recreio, reclusão na classe por meia hora, findos os trabalhos escolares - todas, pela professora, tem sido applicadas reiteradamente (GRUPO ESCOLAR SILVEIRA BRUM, Livro de ofícios, 1919, s/p).

No GEAM, a disciplina, o respeito à hierarquia e às autoridades também eram considerados de extrema importância para o sucesso das atividades escolares. A conduta dos alunos era constantemente avaliada e caso fosse julgada imprópria ao ambiente escolar eram impostos castigos e o discente passava a ser rotulado como mau aluno. Podemos observar na fala da ex-aluna Emilia Portela, como a disciplina escolar e o aprendizado eram avaliados no Grupo:

A professora chamava atenção da gente batendo a régua na mesa. $\mathrm{O}$ bom aluno era aplicado, tirava boas notas e fazia todos os deveres. Eu não era muito boa aluna porque tinha muita dificuldade em matemática. Já o mau aluno era desobediente e não fazia os deveres. Esses recebiam castigos como ficar em pé no canto da sala (ENTREVISTA, julho de 2010).

Além do diretor, outros profissionais também acompanhavam o andamento das atividades escolares e do cotidiano dos Grupos, sendo responsáveis pelo cumprimento das normas administrativas e pedagógicas dessas instituições. Os inspetores regionais de ensino, por exemplo, eram responsáveis por fazer cumprir a lei em vigor, preservando os interesses do governo, sobretudo nos aspectos curriculares e pedagógicos.

$\mathrm{Na}$ análise dos documentos relativos às inspeções realizadas no GEAM, chama atenção algumas recomendações dirigidas aos professores como o incentivo à disciplina e à obediência dos alunos, vistas como fundamentais para a formação integral do indivíduo dentro do ambiente escolar. Esperava-se que os professores primassem pela ordem a fim de que

não seja absolutamente admitida a conversação nas classes, para isso além das próprias simpatias com que se importará a estima e ao respeito dos alunos, o professor se esforce por cultivos praticamente a obediência, por meio de artifícios, de meios insinuantes e, finalmente, empregando os meios disciplinares do Regulamento (GRUPO ESCOLAR ANTÔNIO MARTINS, Relatório de inspeção, 1913, s/p). 
No Grupo de Muriaé também foi possível localizar relatórios de inspeção que tratava desse assunto e de outros aspectos, como o registrado pelo inspetor regional de ensino Raymundo Tavares, em visita ao estabelecimento em 25/10/1912, na qual apontou que:

ao lado de uma freqüência que vem representando o exponte da minha confiança que o estabelecimento vae inspirando à população local, constata-se excelente disciplina dos alunos, attestado forte a favor da direção que vae sendo dada no instituto. As aulas funccionam com toda a regularidade, e os programmas de ensino vão sendo escrupulosamente respeitados (GRUPO ESCOLAR ANTÔNIO MARTINS, Relatório de inspeção, 1912, s/p).

Foram identificadas ainda, nos dois estabelecimentos, recomendações diversas e em momentos diferentes, em relação ao trabalho pedagógico desenvolvido, à relação professor-aluno, às formas de avaliação, ao cotidiano, à rotina que o Grupo deveria assumir e a forma como o diretor do Grupo deveria conduzir o andamento dos trabalhos escolares. Sobre isso, destacamos a seguinte passagem, localizada em um relatório de um inspetor de ensino, que visitou o GESB em 1913:

O programa é inteligentemente executado e apenas consigno neste uma recomendação, relativa às aulas de escripta: prestem os didactas toda a attenção ás mesmas aulas, corrigindo as posições prejudiciaes dos alumnos e procurando obter os melhores trabalhos (GRUPO ESCOLAR ANTÔNIO MARTINS, Relatório de inspeção, 1913, s/p.).

Em Ponte Nova, um relatório de inspeção trouxe contribuições para nosso estudo, sendo este um dos primeiros documentos encontrados e analisados sobre o GEAM, datado do ano de 1913. Neste documento, o inspetor de ensino, Graciano Gomes Calcado, descreve diversas recomendações que foram feitas ao diretor do Grupo a fim de orientá-lo sobre as posições que deveriam ser assumidas para que os trabalhos daquele estabelecimento obtivessem êxito e estivessem em consonância com os ideais republicanos da época.

As primeiras e principais recomendações descritas pelo referido inspetor de ensino, no relatório enviado à Secretaria do Interior no ano de 1913, se referem à rotina que deveria ser assumida pelo Grupo, a relação entre meninos e meninas dentro do estabelecimento, os princípios norteadores do trabalho do diretor escolar e a forma de condução das atividades por parte dos professores. Quanto a este último ponto, um inspetor que visitou o Grupo de Ponte Nova ressalta que é aconselhável que os professores

abstenham-se de administrar as noções do alto de suas cadeiras mas o façam passeando por toda a sala, vigiando, observando, corrigindo os trabalhos dos alunos mas só dos quais não poderá furtar-se a sua observação; que os professores, no recreio, não percam de vista os seus alunos, a fim de que, por um mínimo descuido, não se certifiquem algum inconveniente ou desastre. É indispensável que espalhem sobre os alunos ampla liberdade, sem deixar que tal liberdade transforme-se na perigosa licença por excluir as idéias dos variadíssimos deveres que hão de respeitar (GRUPO ESCOLAR ANTÔNIO MARTINS, Relatório de inspeção, 1913, s/p). 
As palavras do inspetor demonstram que a conduta assumida pelos professores deveria ser rígida e disciplinadora, sempre atentando para as atividades dos alunos, a fim de primar pela ordem e boa convivência. Esse é um dos pontos principais de suas recomendações, o que nos revela que o trabalho dos docentes era visto como um dos aspectos primordiais para a garantia do sucesso das atividades escolares desenvolvidas no Grupo.

As visitas de particulares também assinalam algumas características do funcionamento dos Grupos. Um aspecto que nos chamou a atenção foi a caracterização do método de ensino utilizado no GESB por um grupo de visitantes que caracteriza o modelo escolar do educandário:

É que nelle se conjugam e admiravelmente se casam os melhores mhetodos pedagógicos com a mais séria disciplina e ordem. As licções ministram-se por processos brandos e altamente profícuos fiados na intuição e analyse dos factos múltiplos que constituem a essência da escola moderna. A noção das coisas caminha da mais simples para a mais complexa, ensinando a mente infantil para dellas se apreender suavemente para a vida independente e autônoma do individuo na sociedade [...] nunca imaginamos que em quatro escassos mezes de aulas tanto se conseguisse de resultados esplendidos nesta casa (GRUPO ESCOLAR SILVEIRA BRUM, Relatório de visita de particulares, 1912, $\mathrm{s} / \mathrm{p})$.

O GEAM também desenvolveu suas atividades de ensino pautadas no método intuitivo, conforme se verifica na notícia veiculada pelo jornal O Município, edição do dia 15/05/1913, na qual torna-se de conhecimento geral o fato da Escola ter realizado uma excursão ao Hospital Nossa Senhora das Dores, para que os alunos pudessem interagir com "o mundo a sua volta".

Em relação à forma de contratação docente, verifica-se que o preenchimento das vagas se fazia principalmente por meio da indicação de políticos ou de pessoas influentes na sociedade. Ainda sobre esse assunto identificamos a publicação de edital de concurso de uma vaga para professor adjuncto do "Grupo Escolar de S. Paulo do Muriahé Interior, 6a secção, 27-XI-1917”, conforme consta do Caderno de Ofícios (1917), localizado no Arquivo Público Mineiro. Sobre o Grupo de Ponte Nova, não foram encontrados dados sobre a existência de concursos para a contratação de professores neste período.

Na cidade de Muriaé, após a contratação e antes de iniciar o trabalho docente no educandário, os professores deveriam apresentar documentos sobre sua origem familiar, através do atestado de filiação, bem como deveriam provar boa conduta moral e sanidade física por meio do comprovante de bons antecedentes criminais e de boa saúde, respectivamente. Nos documentos consultados esses três tipos de declaração eram prérequisito para a entrada em exercício no cargo.

No que tange ao perfil dos professores é plausível supor que, em ambos os municípios, estes profissionais possuíam formação prévia de normalistas, pertencendo, majoritariamente, às famílias de prestígio social e político, sendo que a indicação política foi um fator de relevância para a nomeação e efetivação de professoras, principalmente nos primeiros anos de funcionamento. Com o passar do tempo, porém, notamos a presença de docentes não pertencentes às famílias de renome na cidade, embora o apadrinhamento ainda continuasse sendo decisivo para a nomeação.

Tanto o corpo docente do GESB quanto do GEAM, no primeiro ano de suas atividades escolares, contavam com oito docentes. No entanto, percebemos que no GEAM, 
essa categoria era composta apenas de mulheres, o que difere do GESB, que contava com três professores do sexo masculino no corpo de profissionais da escola em 1912.

Outro aspecto relevante observado durante a pesquisa sobre os referidos Grupos Escolares, diz respeito ao fato de terem enfrentado dificuldades semelhantes com o número elevado de alunos matriculados desde sua criação, o que acabou por ocasionar o desdobramento dos trabalhos escolares em dois turnos, ambos no ano de 1913, fato que acabou se repetindo pelos anos subsequentes.

Estes estabelecimentos de ensino funcionavam no horário das 07 às $11 \mathrm{~h}$ e de 12 às 16h. Esta situação era considerada contrária às imposições do regulamento de ensino da época. Assim como acontecia no GEAM, era preciso que o diretor do GESB enviasse regularmente uma correspondência à Secretaria do Interior, solicitando autorização para que o Grupo funcionasse em dois turnos, deixando claros os motivos que estavam levandoo a tomar esta atitude. As justificativas também eram as mesmas para os dois grupos em questão: reduzido número de salas de aula para o elevado número de alunos atendidos.

No GEAM esta situação só foi resolvida na década de 1930 com a mudança do Grupo para um novo prédio construído especialmente com o intuito de atender melhor o elevado número de crianças recebidas anualmente. Já sobre o tempo em que o GESB funcionou em regime de desdobramento de turno, nenhum documento que trouxesse essa informação foi encontrado nos arquivos analisados. Sabemos apenas que o prédio destinado às aulas no Grupo não mudou, permanecendo o mesmo até a atualidade.

Sobre os níveis de frequência nos Grupos, podemos afirmar que eles eram relativamente baixos ao serem comparados com o número de alunos matriculados no início de cada ano letivo, visto que, a título de exemplificação, a média de frequência no GESB em 1912 foi de apenas $61 \%$ dos 568 matriculados $^{3}$, não chegando muitas vezes a $50 \%$ desse total.

Situação semelhante pode ser percebida através da análise do relatório anual de funcionamento alusivo ao primeiro ano de atividades do GEAM, o qual revelou que apenas 365 dos 530 alunos matriculados se mantiveram freqüentes ao longo do ano, ou seja, menos de $70 \%$ dos matriculados foram assíduos às aulas no período letivo em foco. Cabe ressaltar ainda que essa disparidade entre os dados de matrícula e freqüência no GEAM permanece ao longo de todo período analisado ${ }^{4}$.

Muito se tem discutido na área da história da educação sobre a disparidade de dados entre matrícula, frequência e aprovação dos alunos, por isso acreditamos que este seja um problema enfrentado por vários outros estabelecimentos escolares mineiros e brasileiros. É de se supor que as dificuldades financeiras da família e as necessidades de trabalho tenham sido o principal motivo da ausência de crianças pobres às aulas.

A fim de superar essa situação, acumulando bens financeiros e ajudando os alunos mais carentes que procuravam estudar é que foram criadas as Caixas Escolares dos Grupos de Muriaé e Ponte Nova, denominadas respectivamente Delfim Moreira e Vieira Martins. No GESB, a criação dessa organização se deu no mesmo ano de fundação do Grupo, conforme relatado em ofício expedido pela diretoria do GESB em 31 de dezembro de 1912. No GEAM, tal órgão foi fundado no dia 03 de agosto de 1913, após alguns meses do início do funcionamento do Grupo.

Apesar de instalada no mesmo dia da inauguração do Grupo muriaeense, por proposta do Sr. Inspetor escolar Antonio Teixeira e Silva, Gonçalves Couto já relatou - em 1913 - que estaria "tratando, com muito empenho, da organização desta utilissíssima associação" mas que a mesma só poderia funcionar regularmente no futuro ano letivo. Após a leitura de alguns documentos, verificamos que é realmente isso o que ocorre, posto que somente em 5 de agosto de 1914 é que foi possível legalizar a certidão de registro dos 
estatutos da referida sociedade, para que - então - em 27 de setembro de 1914 fosse efetivada a Caixa Escolar Dr. Delfim Moreira mediante às autoridades de ensino.

Em 6 de março de 1913, em ofício do diretor, ficou definida a verba mensal de $20 \$ 000$, referente a essa organização. As atividades desenvolvidas, os recursos obtidos e utilizados, os balanços dos trabalhos dessa organização eram sempre apresentados em atas e relatórios enviados à Secretaria do Interior.

Em Ponte Nova, ao contrário do que observamos em Muriaé, de acordo com a análise dos documentos disponíveis para consulta, podemos perceber que, pelo fato desta instituição sobreviver através de doações financeiras de seus associados, e destas ocorrerem de forma irregular, muitas vezes a Caixa Escolar não era capaz de alcançar seu objetivo.

Em algumas passagens encontradas nos relatórios enviados à Secretaria do Interior pelo diretor do GEAM, é possível perceber a preocupação desse profissional com as atividades da Caixa Escolar, como é o caso do trecho a seguir:

a caixa escolar nada fez pelos alunos pobres e isso porque quase nada arrecadou [...], a arrecadação das mensalidades é também difícil, atento o fato de não haver boa vontade da parte de muitos, em relação à entrada de suas contribuições.[...] a importância recebida não daria para os custeios das despesas indispensáveis e que sempre se impuseram mensalmente (GRUPO ESCOLAR ANTÔNIO MARTINS, Relatório do movimento escolar, 1913, s/p).

Em Muriaé, parece que uma das principais atribuições designadas à Caixa Escolar, a de contribuir para o acesso das crianças pobres ao ensino, foi atingido, e isso é verificado em relatórios de diferentes anos. O documento de 1916 afirmava que "a caixa escolar funcciona regularmente, fornecendo o necessário, aos alumnos pobres do grupo". Conforme já citado anteriormente, é de se supor que essas crianças tinham dificuldade em se manter presente nas aulas dos Grupos estudados, por isso as Caixas Escolares pretendiam erradicar a infrequência desses alunos no educandário.

Além da ausência dos alunos, um acontecimento bastante comum na realidade dos grupos pesquisados diz respeito às faltas do professorado entre os anos de 1912 e 1930. Podemos ressaltar que, entre os documentos analisados, foram as licenças dos docentes que se apresentaram em maior quantidade. As fontes primárias localizadas, até o presente momento, caracterizam o intenso fluxo de afastamento de serviço dos professores regentes do GESB e do GEAM.

No material consultado a priori, foi possível encontrar atestados médicos, cartas, relatórios, atas, ofícios e anotações contendo informações referentes ao afastamento de alguns professores das funções escolares. De acordo com a documentação analisada, foi possível perceber que entre os principais motivos de pedido de afastamento e licenças, estão: problemas de saúde das professoras ou de seus familiares, gestação das docentes, e (em alguns casos) viagens particulares.

Uma das professoras do Grupo de Muriaé apresentou dois atestados em momentos diferentes. No primeiro documento, do ano de 1913, estava diagnosticado um problema de anemia: "Attesto que Estephania M. P [...] acha-se sofrendo de uma anemia profunda em conseqüência de uma hemorraghia interna [...]" (CÂMARA MUNICIPAL DE MURIAÉ, Caderno de ofícios, 1913, s/p).

Já o segundo, datado de 9 de março de 1915, estava justificado por meio de uma endometrite hemorrhagica5: “Attesto que a Exma. Sr. Da Estephania M. do Patrocínio está 
soffrendo de uma endometrite hemorrhagica e precisa de 90 (noventa) dias de licença para seu tratamento." (CÂMARA MUNICIPAL DE MURIAÉ, Caderno de ofícios, 1915, s/p).

Uma outra profissional precisou se ausentar devido a uma paralisia facial, resultado de uma nevrite: "Atesto que a senhorita Laura Vianna soffre de uma nevrite e paralysia facial em conseqüência, necessitando de trez mezes de licença e tratamento, para seu restabelecimento." (CÂMARA MUNICIPAL DE MURIAÉ, Caderno de ofícios, 1914, $\mathrm{s} / \mathrm{p})$.

Nesses três relatos, encontramos especificadas quais eram as enfermidades que acometiam as professoras que saíam de licença naquele momento. Não obstante, encontramos outros documentos que não explicitavam as enfermidades sofridas pelos docentes, mas apontavam para a condição de afastamento dos mesmos da sala de aula.

Em Ponte Nova, as substituições feitas aos professores faltosos eram repassadas à comunidade através dos periódicos de circulação local que, ao apresentarem o balanço anual das atividades do Grupo, salientavam as faltas do professorado e suas respectivas substituições.

A guisa de exemplificação encontramos a notícia vinculada pelo jornal " $O$ Piranga", de 05 de novembro de 1916, onde além de apresentar informações como número total de dias letivos e frequiência dos alunos, ressaltava a ausência de duas professoras:

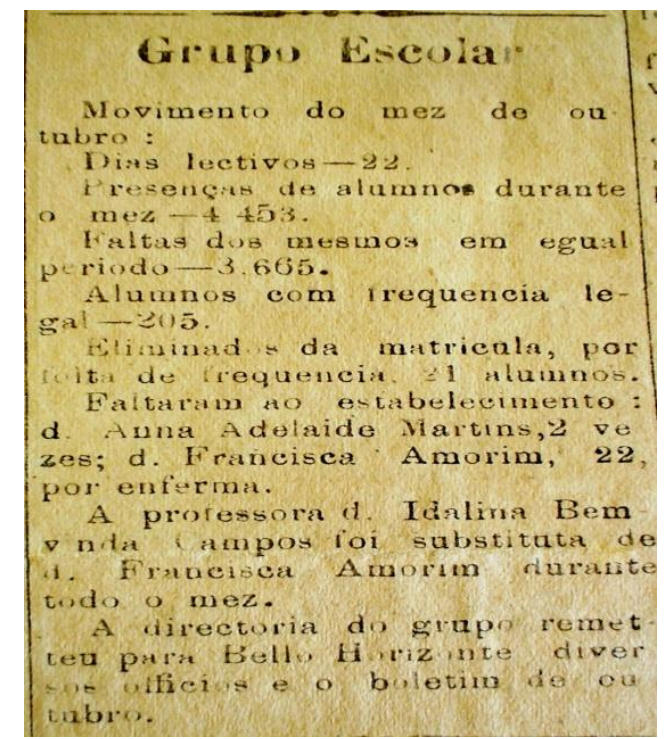

Fonte: Jornal O Piranga, 05 de novembro de 1916.

Arquivo Público da cidade de Ponte Nova - MG.

Através deste informe podemos perceber que duas professoras se ausentaram de suas atividades. Vale ressaltar que ao final do texto, também é repassado aos leitores do jornal que a diretoria do GEAM remeteu para Belo Horizonte diversos documentos oficiais referentes ao ano, juntamente com o boletim do último mês. Estas últimas informações podem ser consideradas como uma prestação de contas à população pontenovense, uma vez que o envio de remessas com o movimento das atividades dos grupos escolares era uma exigência da lei educacional daquela época.

No GEAM, embora as licenças do professorado tenham se apresentado como uma situação constante, as substituições acarretadas por estes pedidos de afastamento, ao que parece, se deram de maneira tranquila, uma vez que não foram encontrados relatos de falta de professoras substitutas ou prejuízo para os alunos de professoras que precisaram se ausentar. 
Em contrapartida, no município muriaeense, foi possível perceber por meio de alguns documentos, que o diretor questionava com frequência à Secretaria do Interior sobre como agir diante de situações adversas que surgiam com os pedidos de licença. Uma dessas situações, datada de 07 de dezembro de 1912, foi o caso de uma professora interina que poderia perder sua cadeira devido à ausência.

Outro destaque relativo às licenças de trabalho dos professores do Grupo Escolar Silveira Brum chamou a atenção pelo fato de que o diretor José Gonçalves Couto, no exercício de suas funções, apresenta seu posicionamento contrário ao consentimento de um pedido de licença de quatorze meses de uma docente do educandário:

essa licença de quatorze mezes pedida pelo supplicante, o que foi mais por um capricho da professora por acinte a essa directoria que, tendo verificado que os alumnos da classe da peticionaria, na sua quase totalidade, se desenvolvesse minimamente atrasados, principalmente em leitura, - disse, mais uma vez, á referida professora que fizesse com que os mesmos tivessem mais adiantamento. Foi o sufficiente para que a professora, fazendo seu grande barulho, me desacatasse, desauctorasse, em plena aula, aos gritos e murros pela mesa, á vista de todos os alumnos, dizendo que se retirava do Grupo sem dar satisfação ao director, a quem não obedecia, ou então pediria uma licença nas mesmas condições, a auctoridades superiores.[...] A peticionaria [...] tem um colégio particular que funcionaria de manha, do qual é a única professora, - ficou excessivamente nervosa de uma irritabilidade insupportavel, a ponto de publicamente, dizer os maiores desaforos á esta directoria, pelo simples facto da referida auctoridade, dentro do regulamento, ter lhe chamado mais uma vez a attençao para irregularidades verificadas em sua classe [...] São Paulo do Muriahé, 25 de maio de 1917 (CÂMARA MUNICIPAL DE MURIAÉ, Caderno de ofícios,1917, s/p, grifo nosso).

Nessa citação, podemos perceber o conflito entre diretor e professora, que acabou por gerar o delongado pedido de afastamento da docente da sala de aula. Assim como nessa situação, podemos supor que outros desentendimentos ocasionados pela tensão das relações profissionais podem ter resultado em pedidos de licença dos professores, que deveriam se adequar às exigências das autoridades superiores.

Após a leitura da bibliografia e consulta aos acervos, percebe-se que as práticas difundidas, tomando como referência o GESB e o GEAM, foram essenciais para a consolidação de uma nova maneira de se fazer a escola primária nos municípios de Muriaé e Ponte Nova, respectivamente.

Feita essa análise mais cuidadosa dos documentos, observamos que a pedagogia desenvolvida nos Grupos foi responsável por delinear o perfil desses estabelecimentos, desde os seus primórdios. Desse modo, o processo de institucionalização da cultura escolar e das práticas educativas, levadas a efeito pelas autoridades pedagógicas, demonstravam uma constante preocupação em manter a disciplina no educandário, obedecendo aos novos preceitos republicanos de "ordem e progresso".

\section{Considerações finais}

O início do funcionamento do Grupo Escolar Silveira Brum na cidade de Muriaé, em 1912, e do Grupo Escolar Antônio Martins, em Ponte Nova no ano de 1913 
representaram o marco inicial de um modelo de escolarização inovador que surge em todo o país, incluindo o Estado de Minas Gerais.

Nos referidos municípios, os educandários criados pretendiam atender as novas exigências advindas desde a abolição da escravidão e a instalação da República, que disseminou uma nova divisão social do trabalho, e a consequente necessidade de controle dos espaços e tempos, que afetam também a organização da jornada escolar.

A nova metodologia de ensino utilizada contava com a figura do diretor como responsável pela organização do trabalho, com a presença de um professor como regente do ensino elementar e um grupo de alunos divididos por séries no ensino primário. Essas modificações nas práticas escolares contribuíram para concretizar uma aprendizagem progressiva, com a gradativa implantação de um trabalho pedagógico sintonizado com os princípios republicanos e de base patriótica.

Além das inovações pedagógicas, a localização espacial conferida aos Grupos demonstrou ao povo muriaeense e pontenovense, a importância que se estava sendo dada à educação naquele momento. As construções em locais centrais contribuíram para que as crianças, antes distantes das salas de aulas, pudessem frequentar uma escola, sem ter a família que pagar por isso.

O estudo comparado a respeito das duas instituições de ensino apontou mais semelhanças que diferenças, o que pode ser justificado pela época de criação, pelo fato de estarem regidos pela mesma legislação e diretriz governamental. Entre as particularidades observadas, destacamos as fontes utilizadas, visto que em Muriaé foram localizadas informações em documentos oficiais sem, no entanto, serem localizados exemplares de periódicos suficientes para analisar outros aspectos da história do educandário, assim como não foram identificados sujeitos que participaram dessa história. Já em Ponte Nova, jornais e entrevistas com ex-alunos possibilitaram uma apreensão mais pormenorizada, a partir de diferentes fontes.

No que diz respeito a aspectos do cotidiano, identificamos a presença de professores do sexo masculino no corpo docente da cidade de Muriaé, o que não ocorreu em Ponte Nova, bem como a mudança do prédio do GEAM, enquanto o GESB funciona até hoje no mesmo endereço.

Acreditamos que, ao estudarmos a história da criação e dos primeiros anos de funcionamento de estabelecimento de ensino dedicados ao ensino primário em Minas Gerais, estamos contribuindo de forma significativa para estudos mais amplos realizados na área de história da educação. Essas discussões de caráter mais particular, que perpassam uma ótica mais micro da história dá significado à construção de estudos macros que garantem a compreensão de parte da trajetória histórica educacional de nosso país.

\section{Referências}

ASSIS, T. R.; AZEVEDO, D. S. Grupo Escolar Antônio Martins (1913-1930): trajetória, memória e cultura escolar. Viçosa: Relatório PIBIC/CNPq, 2009.

CABRAL, T. E. M.; AZEVEDO, D. S. A instalação e constituição do Grupo Escolar nas cidades de Muriaé e Ponte Nova (1907 - 1930): análise de acervo e memórias. Viçosa: Relatório PIBIC/FAPEMIG, 2012.

CARVAS, G. M. A.; AZEVEDO, D. S. A instalação e constituição do Grupo Escolar Antônio Martins na cidade de Ponte Nova (1907 - 1930): análise de acervo e memórias. Viçosa: Relatório PIBIC/CNPq, 2011. 
ENTREVISTA. ministrada em julho de 2010, pela ex-aluna Emilia Portela.

FARIA FILHO, L. M. Dos Pardieiros aos Palácios - Cultura escolar e urbana em Belo Horizonte na Primeira República. Passo Fundo: Ed. Univ., UPF, 2000.

LOPES, A. C.. A escola em festa: Festividades escolares na I República no Piauí.

Disponível em: <http://www.faced.ufu.br/colubhe06/anais/arquivos/

396AntonioPaduaCarvalhoLopes.pdf >. Acesso em: 15 nov 2012. Revista de Historiografia Muriaeense. (1979). Ano II, $\mathrm{n}^{\circ} 2$ - Muriaé - MG, 2011.

\section{Fontes:}

GRUPO ESCOLAR SILVEIRA BRUM. Atas de Instalação, posse, exames. Cadernos de avaliação e certificados de aprovação dos alunos. Relatório do Diretor. Ofícios enviados e recebidos da Secretaria de Educação do Estado. 1912-1930. (Arquivo Escola Estadual Doutor Silveira Brum).

GRUPO ESCOLAR SILVEIRA BRUM. Documentos referentes à Caixa Escolar. Termos de Visitas Oficiais; Termos de Visitas Particulares (1912-1927). (Arquivo Público Mineiro e Escola Estadual Doutor Silveira Brum).

GRUPO ESCOLAR SILVEIRA BRUM. Atas de Instalação e Exames; Relatórios do diretor; Termos de Assentamento e Posse; Visitas Oficiais e Particulares; diplomas; requerimentos; nomeações; decretos; licenças; procurações; frequência dos professores e/ou alunos 1912-1930. (Arquivo Público Mineiro).

CÂMARA MUNICIPAL DE MURIAÉ. Ofícios, circulares e cartas recebidas pela Câmara Municipal, seu presidente e autoridades municipais; Jornais, Biografias, fotografias - 1907 a 1930.

GRUPO ESCOLAR ANTÔNIO MARTINS. Atas de Termo de Posse - 1913 a 1936. (Arquivo Escola Estadual Senador Antônio Martins).

GRUPO ESCOLAR ANTÔNIO MARTINS. Caderno de Atas - 1929 a 1932. (Arquivo Escola Estadual Senador Antônio Martins).

CÂMARA MUNICIPAL DE PONTE NOVA. Ofícios, circulares e cartas recebidas pela Câmara Municipal, seu presidente e autoridades municipais. Jornais da época - 1907 a 1913. 


\section{Notas}

${ }^{1}$ Universidade Federal de Viçosa.

${ }^{2}$ Antônio da Silveira Brum iniciou sua vida política em Muriaé quando o diretório local do Partido Republicano Mineiro (PRM) indicou-o para vereador, sendo o mesmo eleito. Na primeira reunião da Câmara, foi eleito e nomeado Presidente do Executivo Municipal condição esta que era aceitável àquela época. FONTE: Revista de Historiografia Muriaeense, 1979.

${ }^{3}$ Nos documentos analisados a respeito do GESB, encontramos a relação matrícula versus freqüência relativa aos anos de 1912, 1914, 1915, 1918 e 1925 e percebemos que o contingente de alunos que se matriculava no Grupo em todos esses anos era mais elevado do que o número de crianças que permaneciam no mesmo no decorrer do ano. O ano de 1912 é o que houve o maior contraste, com 351 frequentes dos 568 matriculados. Nos anos seguintes, esse desnível também se mostrou evidente: em 1914 foram 663 matriculados contra apenas 485 assíduos. O ano de 1915 foi o que essa relação mais se aproximou, tendo como freqüência cerca de $82 \%$ dos alunos. Já em 1918, o desnível volta a se manifestar, com apenas 368 alunos frequentes dos 564 registrados no início do ano, o que permaneceu no ano de 1925, com 620 inscritos versus 420 assíduos, o que representa uma margem de $67 \%$.

${ }^{4}$ Os documentos analisados durante todo o período em foco (1913-1930) não se apresentam de forma linear devido ao fato de alguns documentos não terem sido localizados e outros se mostrarem incompletos. Sendo assim as informações recolhidas são alusivas apenas aos anos de 1913, 1915, 1919, 1920, 1921, 1923, 1929.

${ }^{5}$ Inflamação e/ou irritação do endométrio (revestimento do útero). FONTE: http://www.api.adm.br/smf4/index.php?topic=351.0 Acesso em: 20 de julho de 2012.

Recebido: Abril/2016.

Aprovado: Maio/2017. 